\title{
Effects of Waterlogging during Grain Filling on Yield Components, Nitrogen Uptake and Grain Quality in Bread Wheat
}

\author{
A.F. Arata ${ }^{1 *}$, M.I. Dinolfo ${ }^{2}$, M. MartíneZ ${ }^{2}$ and L. LÁZARO ${ }^{1}$ \\ ${ }^{1}$ Cátedra de Cereales y Oleaginosas. Laboratorio de Valoración de Calidad Industrial de Trigo, Facultad de \\ Agronomía de Azul, UNCPBA, Av. República de Italia \# 780. 7300 Azul, Buenos Aires, Argentina \\ ${ }^{2}$ Laboratorio de Biología Funcional y Biotecnología (BIOLAB)-INBIOTEC-CONICET-CICBA, Facultad de \\ Agronomía de Azul, UNCPBA, Av. República de Italia \# 780. 7300 Azul, Buenos Aires, Argentina
}

(Received 25 August 2017; Accepted 8 August 2018;

Communicated by A. Goyal)

Waterlogging stress frequently affects wheat production in the current conditions. The aim of this work was to evaluate the effect of waterlogging during grain filling on grain yield components, nitrogen uptake and partitioning and gluten composition and quality in bread wheat. Two greenhouse experiments were conducted under contrasting environmental conditions in Azul, Buenos Aires, in a completely randomized design with three replicates. The cultivar chosen was Klein León and the waterlogging treatment was imposed from 5 days after anthesis to maturity. The effects of waterlogging during grain filling in wheat depended on explored environmental conditions: early sowing $v s$. late sowing. Waterlogging had not significant effects on the most variables at early sowing conditions. However, the delaying in sowing date (higher temperature and radiation) enhance the effects of waterlogging: i) reducing grain weight by $41 \%$ and total nitrogen uptake by $51 \%$; ii) reducing the ratio between the contents of high and low molecular weight glutenin subunits, affecting gluten composition; and iii) increasing the sodium dodecyl sulfate test from 79 to $108 \mathrm{~mm}$, which correlates positively with the gluten strength. Reductions in grain weight due to waterlogging during grain filling affect the milling quality, although changes in protein composition may increase or maintain the gluten strength (SDSS) under particular conditions.

Keywords: nitrogen, protein, yield components, waterlogging, wheat

Abbreviations: E1: experiment during 2015; E2: experiment during 2016; GLI: gliadins; GLU: glutenins; HMW-GS: high molecular weight glutenin subunits; LMW-GS: low molecular weight glutenin subunits; GY: grain yield per shoot; GS: grains per spike; GW: grain weight; $\mathrm{AB}$ : above ground biomass per shoot; HI: harvest index; SW: spike weight; SL: shoot and leaf weight; SF: spike fertility coefficient; GN\%: nitrogen concentration in grain; SN\%: nitrogen concentration in stover; GN: nitrogen uptake in grain; SN: nitrogen uptake in stover; TN: total nitrogen uptake; NHI: nitrogen harvest index; Pro\%: protein content; SDSS: sodium dodecyl sulfate sedimentation test; SDSS/Pro: specific SDSS; GLI/ GLU: ratio between the contents of gliadins and glutenins; HMW-GS/LMW-GS: ratio between the contents of high and low molecular weight glutenin subunits; $\omega$-gli $/ \alpha-\beta-\gamma$-gli: ratio between the contents of $\omega$-gli and $\alpha-\beta-\gamma$-gli

*Corresponding author; E-mail: arataa@faa.unicen.edu.ar; Phone/Fax: +54 2281433291 


\section{Introduction}

Regarding climate change, waterlogging is one of the abiotic factors whose occurrence will further increase due to the increase in rainfalls (Parry et al. 2007). Water-saturated soil implies negative effects on the root with consequences on the shoot physiology producing several damages in crop production. Under waterlogging conditions, ethylene rapidly increases inside the plant as a primary signal for adaptation to this condition. Moreover, this stress results in anoxic soils (absence of $\mathrm{O}_{2}$ ) changing from aerobic to anaerobic conditions. Therefore, oxygen deficiency increases leaf senescence, reduces root growth and tillering and affects grain yield by reducing the kernel number and weight depending on the duration of waterlogging events, the development stage of crop upon the last and the capacity of the cultivar to adapt to this condition (De San Celedonio et al. 2014; Arduini et al. 2016). Waterlogging during grain filling stages reduces grain yield by reduction in dry matter accumulation and nitrogen uptake in the shoot, redistribution of stored photosynthates to the grain and the conversion capacity from carbohydrate to starch (Jiang et al. 2008). As a strategy for adapting to waterlogging, several roots form aerenchyma in the cortex which facilitates the $\mathrm{O}_{2}$ diffusion upon this condition (Herzog et al. 2016; Loreti et al. 2016).

The most important protein fractions, the gliadins (GLI) and glutenins (GLU) are the primary determinant of bread-making quality. Glutenins are multimeric aggregates of high molecular weight (HMW-GS) and low molecular weight (LMW-GS) subunits. HMW-GS are encoded by Glu-A1, Glu-B1 and Glu-D1 loci and determine the formation and amount of glutenin macropolymer (GMP) which is closely correlated with baking quality (Yue et al. 2007). Gliadins are mainly monomeric proteins and are divided into four structural types called $\alpha$-, $\beta$-, $\gamma$ - and $\omega$-gliadins. Different alleles of these loci and the proportions of each protein fraction also affect grain quality of wheat (Payne et al. 1987; Wieser, 2007). Several researchers have observed that the grain protein content and particularly HMW-GS were affected upon waterlogging treatments (Jiang et al. 2008).

The industrial quality of bread wheat is a multidimensional attribute determined by genotypic characteristics, structural of the grain and of the reserves stored in the endosperm, especially starch and proteins (Peña et al. 2002). Sodium dodecyl sulfate sedimentation test (SDSS) stands out among the predictive parameters of quality that require little amount of sample, since it correlates closely with the gluten strength (Dick and Quick 1983; Lerner et al. 2004, 2006). In addition, previous reports showed a relation between the nitrogen harvest index (nitrogen partitioning) and some parameters of industrial quality in bread wheat (Lerner et al. 2016). This justifies the integrated study of these variables at conditions of waterlogging stress. On the other hand, the waterlogging-induced effects on wheat grain composition and quality have so far been examined in very few studies, whereby it is not yet possible to draw sound inferences on these effects (Ashraf 2014).

The aim of this work was to evaluate the effect of waterlogging during grain filling on grain yield components, nitrogen uptake and their partitioning and gluten composition and quality in bread wheat. 


\section{Materials and Methods}

\section{Plant material and growing conditions}

Two greenhouse experiments were conducted during 2015 (E1) and 2016 (E2) at the Facultad de Agronomía ( $36^{\circ} 41^{\prime} \mathrm{S}, 5^{\circ} 48^{\prime} \mathrm{O}$ ), Universidad Nacional del Centro de la Provincia de Buenos Aires. In order to use a cultivar unstable in terms of grain quality, Klein León was selected based on short cycle length, high yield potential, lodging resistance and poor baking quality. In previous field experiments (Lerner et al. 2016), this cultivar showed yield means of 4680 and $5420 \mathrm{~kg} / \mathrm{ha}$ (dry basis) for unfertilized and nitrogen fertilized treatments, respectively. At the same conditions, protein content varied between 10.6 and $13.2 \%$, while baking strength varied between 143 and $198 \mathrm{~J} \mathrm{10}{ }^{-4}$. Also, Klein Leon was classified in Quality group 3 (lowest baking quality), which is established by the national organism for seed registration (INASE, Argentina) based on phenotypic attributes.

The plants were grown in $7 \mathrm{~L}$ pots containing $4.8 \mathrm{~kg}$ of clay loam soil with the following characteristics: $\mathrm{pH}=6.9(1: 2.5$ in water), N-nitrate $=18.62 \mathrm{~kg} \mathrm{~N} /$ ha (by reflectometry), S-sulfate $=17 \mathrm{ppm}$ (by turbidimetry), available $\mathrm{P}=13.84 \mathrm{ppm}$ (Bray and Kurtz 1945 ) and organic matter $=3.51 \%$ (Walkley and Black 1934). Ten seeds previously treated with Tenacius ${ }^{\circledR}$ (difenoconazole + metalaxil-M+tiametoxam) were sowed per pot. The sowing date was $3^{\text {rd }}$ September 2015 for E1 and $1^{\text {st }}$ April 2016 for E2. Plants were fertilized with $0.4 \mathrm{~g}$ of PDA at sowing, $0.9 \mathrm{~g}$ of urea and $0.2 \mathrm{~g}$ of $\mathrm{Ca}_{2} \mathrm{SO}_{4}$ in split doses at Z1.2 and Z2.3 (Zadoks et al. 1974). The anthesis (Z6.5) date was 29th October 2015 for E1 and $7^{\text {th }}$ June 2016 for E2. The maturity (Z9.9) date was $4^{\text {th }}$ December 2015 for E1 and $24^{\text {th }}$ July 2016 for E2. During crop cycle, fungicide (Orquesta ${ }^{\circledR}$ Ultra: fluxapyroxad + epoxyconazole + pyraclostrobin) and insecticide (cypermethrin) were applied in both years and weeds were removed by hand. Mean temperature and global radiation data were registered (Table 1).

Table 1. Period duration, mean temperature and mean radiation for the sowing-anthesis phase and the anthesis-maturity phase in experiment 1 (E1) and experiment 2 (E2)

\begin{tabular}{|l|c|c|c|}
\hline \multirow{2}{*}{ Period duration (days) } & Experiment & Sowing-anthesis & Anthesis-maturity \\
\cline { 2 - 4 } & E1 & 56 & 36 \\
\hline \multirow{2}{*}{ Mean temperature $\left({ }^{\circ} \mathrm{C}\right)$} & E2 & 68 & 47 \\
\cline { 2 - 4 } & E1 & 21.9 & 24.9 \\
\hline \multirow{2}{*}{ Mean radiation $\left(\mathrm{MJ} \mathrm{m}^{-2} \mathrm{~d}^{-1}\right)$} & E2 & 20.8 & 20.3 \\
\cline { 2 - 4 } & E1 & 6.7 & 10.4 \\
\hline
\end{tabular}

\section{Waterlogging treatment}

Experimental design was completely randomized with three replicates. The waterlogging treatment (W treatment) was imposed from 5 days after anthesis to maturity placing pots into containers with $1 \mathrm{~cm}$ layer of free water above the surface. Control pots (T treatment) 
from sowing to maturity and waterlogging pots from sowing to 5 days after anthesis were daily irrigated as needed and well drained.

\section{Measurements}

Regarding yield components, grain yield per shoot (GY), grains per spike (GS), grain weight $(\mathrm{GW})$, above ground biomass per shoot $(\mathrm{AB})$, harvest index $(\mathrm{HI}=\mathrm{GY} / \mathrm{AB})$, spike weight (SW), shoot and leaf weight (SL) and spike fertility coefficient ( $\mathrm{SF}=\mathrm{GY} / \mathrm{SW}$ ) were measured. Harvested samples were dried in stove at $50{ }^{\circ} \mathrm{C}$ for $72 \mathrm{~h}$ and then were milled. Nitrogen concentration was determined in grain (GN\%) and stover (SN\%) by microKjeldahl. Nitrogen uptake in grain $(\mathrm{GN}=\mathrm{GY} * \mathrm{GN} \% / 100)$, in stover $[\mathrm{SN}=(\mathrm{AB}-\mathrm{GY}) * \mathrm{SN} \% / 100]$ and total $(\mathrm{TN}=\mathrm{GN}+\mathrm{SN})$ and nitrogen harvest index $(\mathrm{NHI}=\mathrm{GN} / \mathrm{TN})$ were calculated. Protein content (Pro\%) was calculated by multiplicating GN\% by 5.75 factor. Sodium dodecyl sulfate sedimentation test was used to predict the gluten strength (SDSS; Dick and Quick 1983). Specific SDSS (SDSS/Pro) was calculated by dividing SDSS by Pro\%. Glutenin and gliadin proteins were extracted by sequential extraction method according to Gupta and MacRitchie (1991) and were separated by SDS-PAGE $(\mathrm{T}=13.5 \%)$. The gel was stained with $0.05 \%$ Coomassie Brilliant Blue R250 for $24 \mathrm{~h}$ and discolored in TCA $12 \%$ for $48 \mathrm{~h}$ and finally in distilled water for $24 \mathrm{~h}$. The resulting gels were scanned and analyzed by using TotalLab v1.10 demo software to measure the intensity of the pixel as an abundance indicator. Background subtraction was applied and the content of protein of each subunit or fraction was expressed as a relationship among fractions in order to avoid the variability due the staining process. Thus, the ratio between contents of gliadins and glutenins (GLI/GLU), the ratio between contents of high molecular weight and low molecular weight glutenin subunits (HMW-GS/LMW-GS), the contents of different glutenin subunits encoded by Glu1 loci relative to total high molecular weight glutenins (Glu-A1x/HMW, Glu-B1x/HMW, Glu-B1y/HMW, Glu-D1x/HMW, Glu-D1y/HMW) and the ratio between $\omega$-gliadins and $\alpha-\beta$ - $\gamma$-gliadins $(\omega$-gli $/ \alpha-\beta$ - $\gamma$-gli) were determined.

\section{Statistical analysis}

ANOVA analyses were carried out and the levels of significance were established by using Tukey tests at $\mathrm{p}<0.05$. Infostat software was used (Di Rienzo et al. 2017).

\section{Results}

\section{Yield components}

The GY in E2 was higher compared to E1. Although the differences were not significant, the $\mathrm{W}$ treatment trended to reduce the GY especially in E1. The GS was affected by the experiment being $\mathrm{E} 2$ higher than $\mathrm{E} 1$. The $\mathrm{W}$ treatment reduced $\mathrm{GW}$ by $41 \%$ only in $\mathrm{E} 1$. Instead HI was not affected, AB showed the same behavior as GY. The SW was only affected by experiment being E1 higher than E2. The mean of SL in E2 was higher than E1 and the W treatment reduced SL by $21 \%$ on average. Finally, SF was not affected by factors (Table 2). 


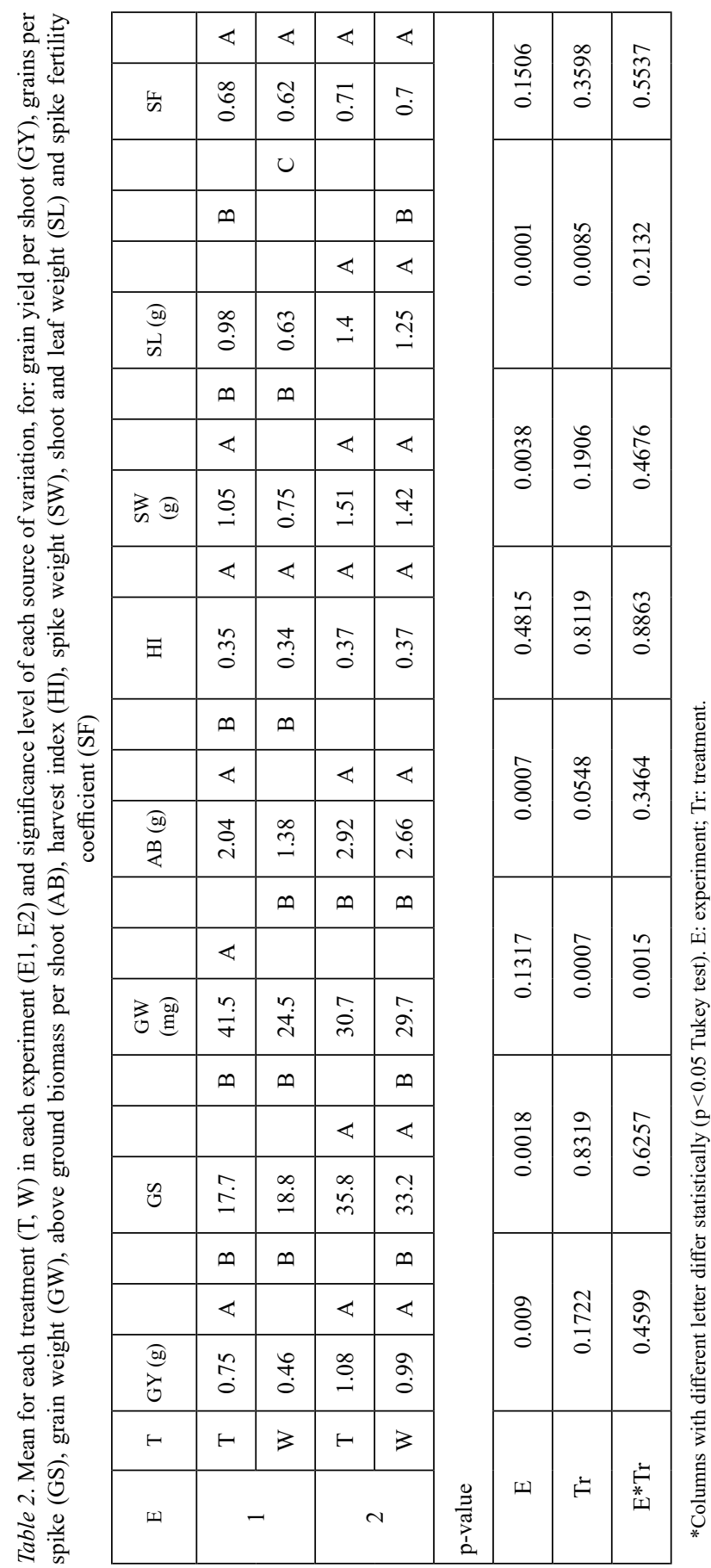




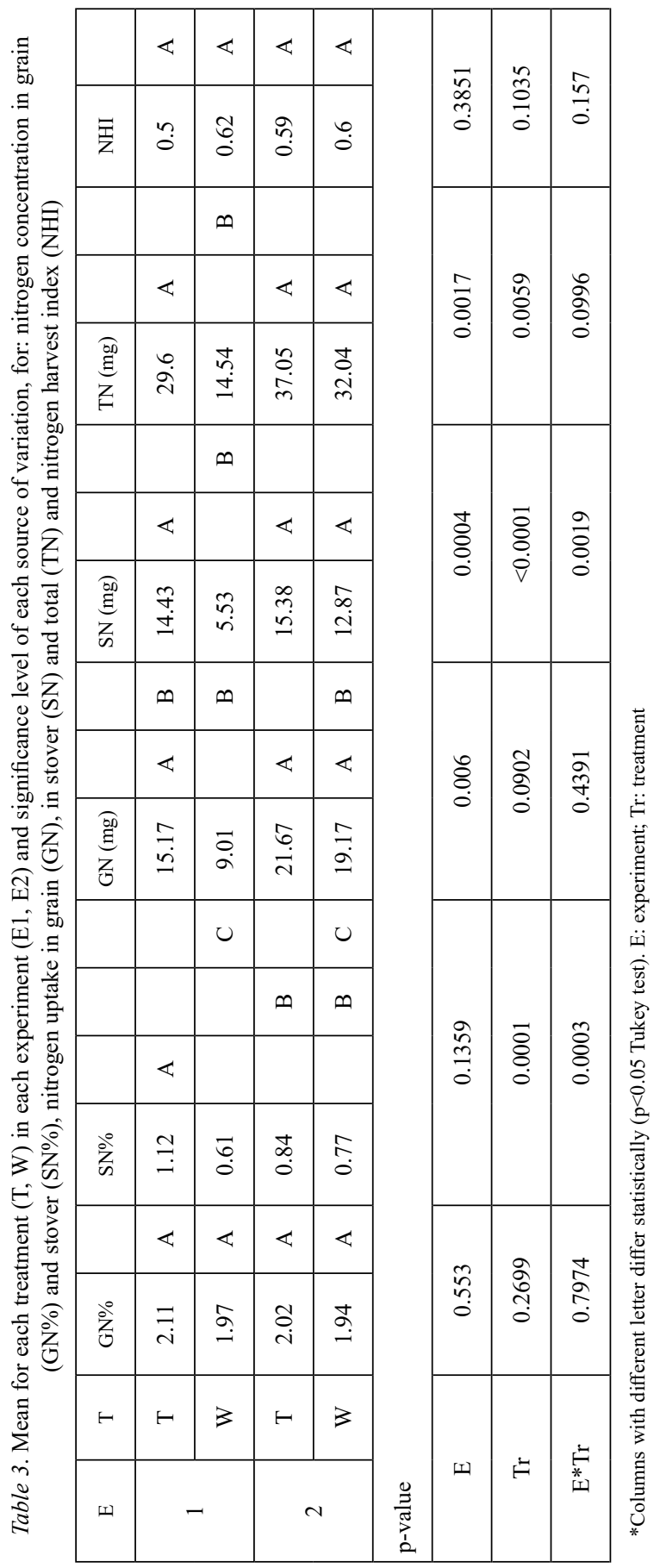

Cereal Research Communications 47, 2019 
E1

\section{GLU}
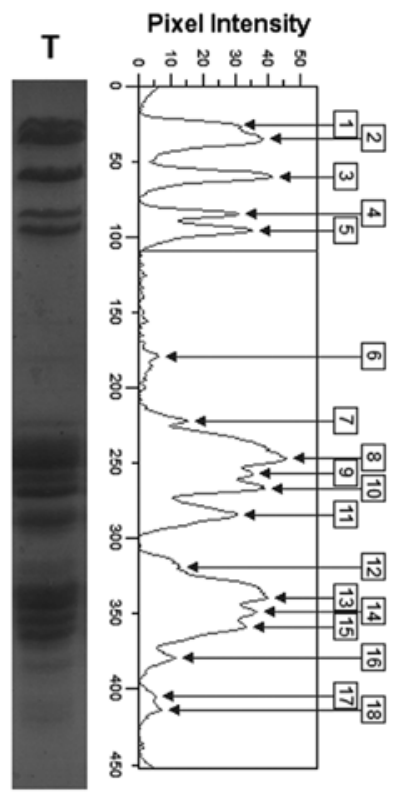

Pixel Intensity

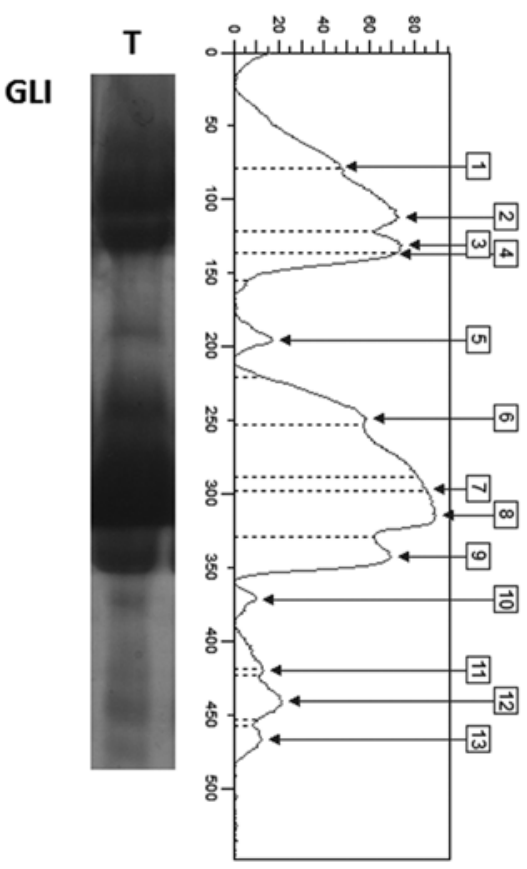

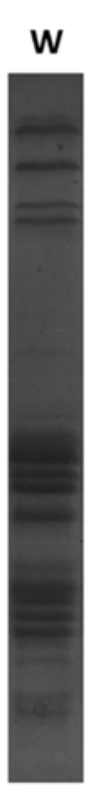

Pixel Intensity

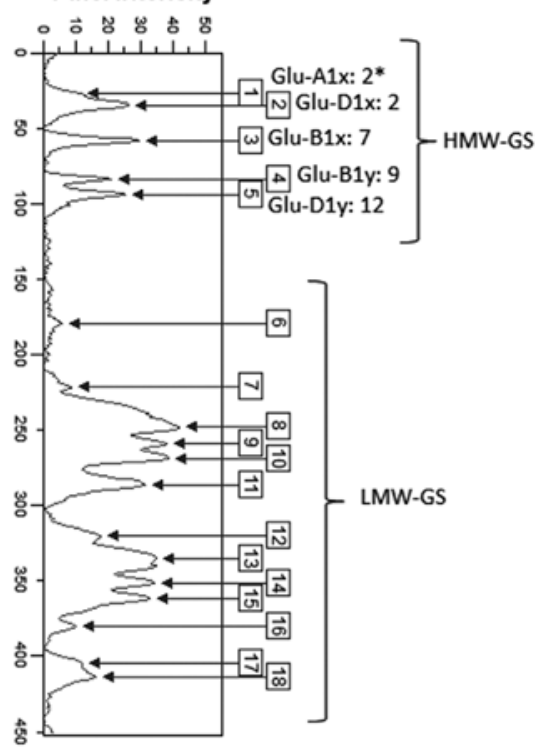

Pixel Intensity

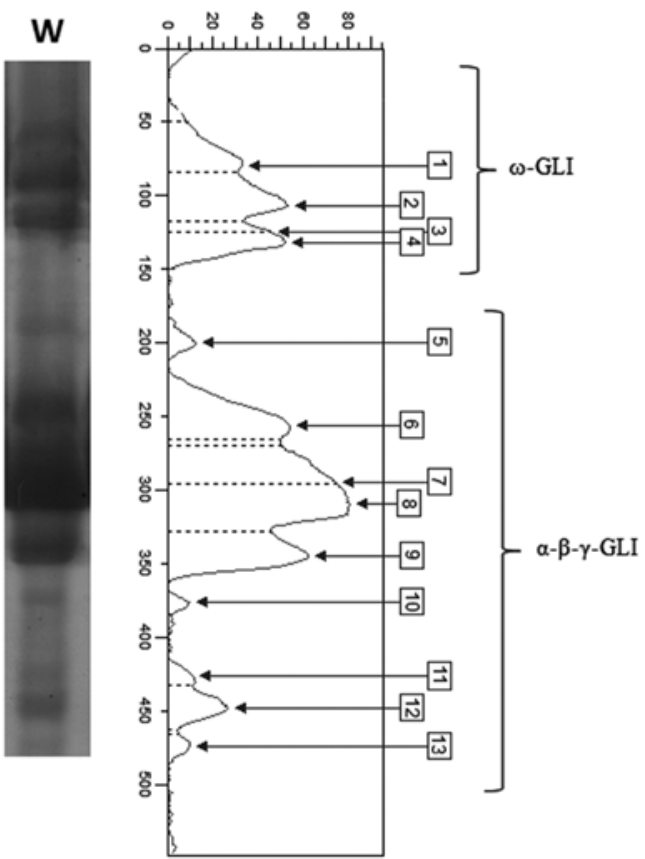

Figure 1. Fractions of polyacrylamide gels revealing the glutenins (GLU) and gliadins (GLI) band patterns for control treatment $(\mathrm{T})$ and waterlogging treatment $(\mathrm{W})$ in experiment 1 (E1) and densitometry of each fraction.

The pixel intensity indicates the abundance of each protein subunit 


\section{Nitrogen uptake and partitioning}

Instead GN\% was not affected by factors, the W treatment reduced SN\% by $46 \%$ only in $\mathrm{E} 1$. The mean of GN in E2 was $69 \%$ higher than in E1 and the W treatment reduced SN by $62 \%$ only in E1. Thus, the mean of TN in E2 was $57 \%$ higher than in E1 and the $\mathrm{W}$ treatment reduced this parameter by $30 \%$ on average. Although the differences were not significant, the W treatment trended to increase the NHI especially in E1 (Table 3).

\section{Grain composition and quality}

The HMW-GS allelic composition was: $2 *$ for $G l u-A 1,7+9$ for $G l u-B 1$ and $2+12$ for Glu-D1 (Fig. 1). The W treatment reduced by $12 \%$ the GLI/GLU ratio without differences among experiments (Fig. 2a). In E1 the HMW-GS/LMW-GS ratio in W treatment
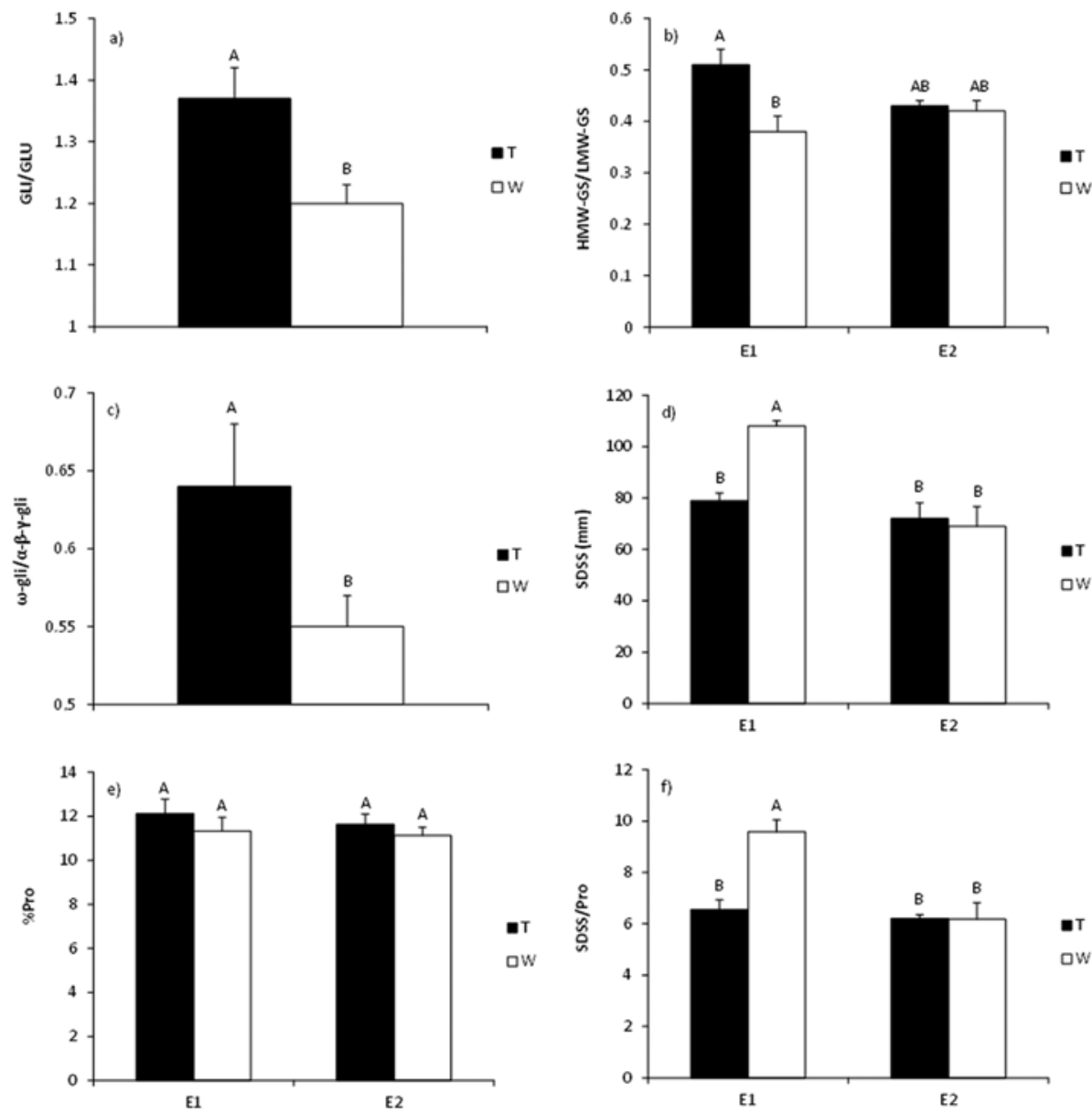

Figure 2. Changes in GLI/GLU ratio (a), HMW-GS/LMW-GS ratio (b), $\omega$-gli/ $\alpha-\beta-\gamma$-gli ratio (c), SDS sedimentation (d), protein content (e) and specific SDSS (f) of the control treatment (T) and the waterlogging treatment (W). Means with different letter differ statistically ( $\mathrm{p}<0.05$ Tukey Test). E1: experiment 1; E2: experiment 2 
was lower (25\%) than control while in E2 differences were not significant (Fig. 2b; Fig. 1). Regarding GLI, the $\mathrm{W}$ treatment reduced in $14 \%$ the $\omega$-gli $/ \alpha-\beta-\gamma$-gli on average in both experiments (Fig. 2c). The proportion of each HMW-GS (Glu-A1x/HMW, Glu-B1x/ HMW, Glu-B1y/HMW, Glu-D1x/HMW, Glu-D1y/HMW) did not show differences between treatments and experiments (data not shown; Fig. 1). In E1, the SDSS increased by $37 \%$ in $\mathrm{W}$ treatment compared to control while in E2 differences were not significant (Fig. 2d). The Pro\% was not significantly affected by treatment and experiment (Fig. 2e), while the $\mathrm{W}$ treatment increased by $46 \%$ the SDSS/Pro only in E1 (Fig. 2f).

\section{Discussion}

Several authors have evaluated the effect of waterlogging in crops but few showed a simultaneous analysis of yield components, nitrogen partitioning and grain quality in bread wheat. This work analyzed the post-anthesis waterlogging effects on a high yielding and short-season bread wheat cultivar from Argentina in two contrasting environments under greenhouse conditions. One of them (E1) was carried out in a late sowing date with higher mean temperature and radiation, especially during grain filling, resulting in a shorter cycle length. On the other hand, the other experiment (E2) was carried out in an early sowing date with lower mean temperature and radiation, resulting in a longer cycle length.

$\mathrm{AB}, \mathrm{GY}, \mathrm{GS}$ and $\mathrm{SW}$ were significantly higher in $\mathrm{E} 2$ than in $\mathrm{E} 1$, while no changes were observed in HI and SF. This could be explained by the lower mean temperature and consequently longer duration of the pre- and post-anthesis stages in E2. Waterlogging treatment trended to reduce GY due to a significant reduction of GW under conditions of high temperature and radiation (E1). De San Celedonio et al. (2014) reported that the time around anthesis was the most susceptible period to waterlogging in wheat and barley. In the same way, these authors observed that exposing the crop to more stressful conditions, e.g. delaying sowing date, magnified the negative responses to waterlogging. On the other hand, Arduini et al. (2016) reported that waterlogging during tillering stage in wheat reduced grain yield due to a reduction in grain number without changes in grain weight, while Arguello et al. (2016) observed decreases in both components.

The experiment conditions modified the waterlogging effects on $\mathrm{N}$ parameters. Thus, $\mathrm{W}$ treatment decreased \% $\mathrm{SN}$ only in E1, while \%GN was not affected. Also, this stress reduced $\mathrm{TN}(-52 \%)$ in $\mathrm{E} 1$ due to a reduction more proportional in $\mathrm{SN}(-62 \%)$ than in GN $(-41 \%)$. Therefore, the $\mathrm{W}$ treatment trended to increase $\mathrm{N}$ partitioning to grain. Similarly, Jiang et al. (2008) reported that post-anthesis waterlogging depressed carbon accumulation and $\mathrm{N}$ uptake in shoot. This could be explained by a decrease in the root hydraulic conductivity which alters the water balance of shoots of plants under waterlogging conditions. In addition, arrest in root elongation upon a pronounced waterlogging (like in this experiment), thereby leading to a reduced soil exploration and reduced surface area for uptake of nutrients (Herzog et al. 2016).

The Glu-1 quality score (Payne et al. 1987) for the HMW-GS composition of Klein Leon was 7, showing poor bread making quality. The presence of HMW-GS associated 
with dough weakness (as $2+12$ in Leon) appears to confer minor tolerance to heat stress. This is related to the fact that lines possesing this subunit type start accumulating large polymers several days later than lines with HMW-GS related to dough strength (as $5+10$ ) (Naeem et al. 2012). Therefore, the study of post-anthesis waterlogging effects on quality parameters in this type of unstable cultivars result of special interest.

Waterlogging altered gluten composition in both experiment conditions, showing reductions in GLI/GLU and $\omega$-gli/ $\alpha-\beta$ - $\gamma$-gli. Also, this stress decreased HMW-GS/LMWGS only under high temperature and radiation conditions during grain filling (E1), while the proportion of each HMW-GS was not affected. Similarly, Jiang et al. (2009) reported that post-anthesis waterlogging reduced the accumulation of HMW-GS during the whole grain filling phase.

Changes in gluten composition due to $\mathrm{W}$ treatment coincided with an increase in gluten strength (SDSS) in E1 conditions, while no variation were observed in Pro\%. This generated an increase in specific SDSS, indicating an improvement in protein quality. Other authors reported that grain protein content and glutenin macropolymers were lower under waterlogging compared to the control, but quality predictor studies such as SDSS were not carried out (Jiang et al. 2009). In particular, Olgun et al. (2008) observed that protein content only was reduced when waterlogging remained more than 20 days after flowering in wheat. Reductions in grain weight due to waterlogging during grain filling affect the milling quality, although changes in protein composition may increase or maintain the gluten strength (SDSS) under particular conditions.

\section{Conclusion}

Our results show that the effects of waterlogging during grain filling in wheat depend on explored environment under greenhouse conditions. Thus, waterlogging under late sowing conditions: i) reduces grain weight and total nitrogen uptake; ii) reduces HMW-GS/ LMW-GS, affecting gluten composition; and iii) increases gluten strength and specific SDSS.

\section{Acknowledgements}

We are grateful to Lic. Mariana Oyarzabal for English assistance. This research was partially funded by Facultad de Agronomía, Universidad Nacional del Centro de la Provincia de Buenos Aires.

\section{References}

Arduini, I., Orlandi, C., Pampana, S., Masoni, A. 2016. Waterlogging at tillering affects spike and spikelet formation in wheat. Crop Pasture Sci. 67:703-711.

Arguello, M.N., Mason, R.E., Roberts, T.L., Subramanian, N., Acuña, A., Addison, C.K., Lozada, D.N., Randall, G.M., Gbur, E. 2016. Performance of soft red winter wheat subjected to field soil waterlogging: Grain yield and yield components. Field Crop. Res. 194:57-64. 
Ashraf, M. 2014. Stress-induced changes in wheat grain composition and quality. Crit. Rev. Food Sci. 54:15761583.

Bray, R.H., Kurtz, L.T. 1945. Determination of total, organic and available forms of phosphorus in soil. Soil Sci. 59:39-45.

De San Celedonio, R.P., Abeledo, G., Miralles, D. 2014. Identifying the critical period for waterlogging on yield and its components in wheat and barley. Plant Soil 378:265-277.

Di Rienzo, J.A., Casanoves, F., Balzarini, M.G., Gonzalez, L., Tablada, M., Robledo, C.W. InfoStat versión 2017. Grupo InfoStat, FCA, Universidad Nacional de Córdoba, Argentina. URL http://www.infostat.com.ar

Dick, J.W., Quick, J.S. 1983. A modified screening test for rapid estimation of gluten strength in early-generation durum wheat breeding lines. Cereal Chem. 60:315-318

Gupta, R.B., MacRitchie, F. 1991. A rapid one-step one dimensional SDS-procedure for analysis of subunit composition of glutenin in wheat. J. Cereal Sci. 14:105-109.

Herzog, M., Striker, G.G., Colmer, T.D., Pedersen, O. 2016. Mechanisms of waterlogging tolerance in wheat- a review of root and shoot physiology. Plant Cell Environ. 39:1068-1086.

Jiang, D., Fan, X., Dai, T., Cao, W. 2008. Nitrogen fertilizer rate and post-anthesis waterlogging effects on carbohydrate and nitrogen dynamics in wheat. Plant Soil 304:301-314.

Jiang, D., Yue, H., Wollenweber, B., Tan, W., Mu, H., Bo, Y., Dai, T., Jing, Q., Cao, W. 2009. Effects of postanthesis drought and waterlogging on accumulation of high-molecular-weight glutenin subunits and glutenin macropolymers content in wheat grain. J. Agron. Crop Sci. 195:89-97.

Lerner, S.E., Cogliatti, M., Ponzio, N.R., Seghezzo, M.L., Molfese, E.R., Rogers, W.J. 2004. Genetic variation for grain protein components and industrial quality of durum wheat cultivars sown in Argentina. J. Cereal Sci. 40:161-166.

Lerner, S.E., Seghezzo, M.L., Molfese, E.R., Ponzio, N.R., Cogliatti, M., Rogers, W.J. 2006. N- and S-fertiliser effects on grain composition, industrial quality and end-use in durum wheat. J. Cereal Sci. 44:2-11.

Lerner, S.E., Arata, A.F., Arrigoni, A.C. 2016. Relationship between nitrogen use attributes and industrial quality in Argentine bread wheat cultivars (Triticum aestivum L.) with different composition of gluten. RIA 42:29-40.

Loreti, E., van Veen, H., Perata, P. 2016. Plant responses to flooding stress. Curr. Opin. Plant Biol. 33:64-71.

Naeem, H.A., Paulon, D., Irmak, S., MacRitchie, F. 2012. Developmental and environmental effects on the assembly of glutenin polymers and the impact on grain quality of wheat. J. Cereal Sci. 56:51-57.

Olgun, M., Metin Kumlay, A., Cemal Adiguzel, M., Caglar, A. 2008. The effect of waterlogging in wheat ( $T$. aestivum L.). Acta Agr. Scand. B-S. P. 58:193-198.

Parry, M.L., Canziani, O.F., Palutikof, J.P., van der Linden, P.J., Hanson, C.E. 2007. Climate Change 2007: Impacts, Adaptation and Vulnerability. Contribution of Working Group II to the Fourth Assessment Report of the Intergovernmental Panel on Climate Change. IPCC. Cambridge.

Payne, P.I., Nightingale, M.A., Krattiger, A.F., Holt, L.M. 1987. The relationship between HMW glutenin subunit composition and the bread-making quality of British-grown wheat varieties. J. Sci. Food Agr. 40:51-65.

Peña, R.J., Trethowan, R., Pfeiffer, W.H., Van Ginkel, M. 2002. Quality (end-use) improvement in wheat: compositional, genetic, and environmental factors. J. Crop Prod. 5:1-37.

Walkley, A., Black, I. 1934. An examination of the Degtjareff method for determining soil organic matter and a proposed modification of the chromic acid titration method. Soil Sci. 37:29-38.

Wieser, H. 2007. Chemistry of gluten proteins. Food Microbiol. 24:115-119.

Yue, H., Jiang, D., Dai, T., Qin, X., Jing, Q., Cao, W. 2007. Effect of nitrogen application rate on content of glutenin macropolymer and high molecular weight glutenin subunits in grains of two winter wheat cultivars. J. Cereal Sci. 45:248-256.

Zadoks, J.C., Chang, T.T., Kouzak, C.F. 1974. A decimal code for the growth stage of cereals. Weed Res. 14:415-421. 